\title{
Knai and colleagues' response to comments of the Portman Group in news story about their research on the "responsibility deal" on alcohol
}

\author{
Cécile Knai senior lecturer in public health policy, Mark Petticrew professor of public health evaluation, \\ Nicholas Mays professor of health policy, Mary Alison Durand lecturer, Elizabeth Eastmure honorary \\ research fellow
}

Policy Innovation Research Unit, Faculty of Public Health and Policy, London School of Hygiene and Tropical Medicine, London WC1E 7HT, UK

Some statements from the Portman Group about our evaluation of the "responsibility deal" on alcohol are seriously misleading. ${ }^{1}$

The statement about our "track record of campaigning against voluntary agreements" is inaccurate. One of our first studies set out to understand the characteristics of effective voluntary agreements, ${ }^{2}$ which should be based on clearly defined, evidence based, and quantifiable targets; should push partners to go beyond "business as usual"; and should include penalties for not delivering the pledges. Our new findings show that the responsibility deal's pledges do not meet these criteria. ${ }^{34}$

The Portman Group also accuses us of ignoring "official government data showing the achievements of the responsibility deal." We thoroughly and systematically examined available data provided by partners themselves about their activities, as well as evidence that any of these activities could have a positive impact on public health. Our conclusions were that any impact was likely to be limited, and that organisations had generally signed up to things they were already doing. Our findings regarding the one billion unit pledge support the Sheffield analysis. $^{5}$

The Portman Group also claims that our analyses of the activities of the Alcohol Network "undermine the vital work done to improve public health." We fail to see how an analysis of whether the responsibility deal alcohol pledges will improve public health can undermine efforts to improve public health

Finally, because alcohol related harms continue to be a major and costly public health problem in England, we restate our conclusions that effective interventions must be at the forefront of any meaningful action and need to go beyond business as usual. The Public Health Responsibility Deal should be first and foremost about improving public health.

Competing interests: We are the research team at the Policy Innovation Research Unit (PIRU), funded to conduct the evaluation of the responsibility deal. PIRU is an independent research unit based at the London School of Hygiene and Tropical Medicine, funded by the Department of Health Policy Research Programme. Sole responsibility for this research lies with the authors and the views expressed are not necessarily those of the Department of Health. The Department of Health played no role in the design of the study, the interpretation of the findings, the writing of the papers referred to in this response, or the decision to submit.

Full response at: www.bmj.com/content/350/bmj.h1671/rr-0.

Hawkes N. Industry's pledges to limit harms of alcohol are unlikely to work, research finds. BMJ 2015;350:h1671. (26 March.)

2 Bryden A, Petticrew M, Mays N, et al. Voluntary agreements between government and business-a scoping review of the literature with specific reference to the Public Health Responsibility Deal. Health Policy 2013;110:186-97.

3 Knai C, Petticrew M, Durand MA, et al. The Public Health Responsibility deal: has a public-private partnership brought about action on alcohol reduction? Addiction 2015; published online $26 \mathrm{Mar}$; doi:10.1111/add.12892.

4 Knai C, Petticrew M, Durand MA, et al. Are the Public Health Responsibility Deal alcohol pledges likely to improve public health? An evidence synthesis. Addiction 2015; published online 26 Mar; doi:10.1111/add.12855.

5 Holmes J, Angus C, Meier PS. UK alcohol industry's "billion units pledge": interim evaluation flawed. BMJ 2015;350:h1301. (24 March.) 